Provided for non-commercial research and education use. Not for reproduction, distribution or commercial use.

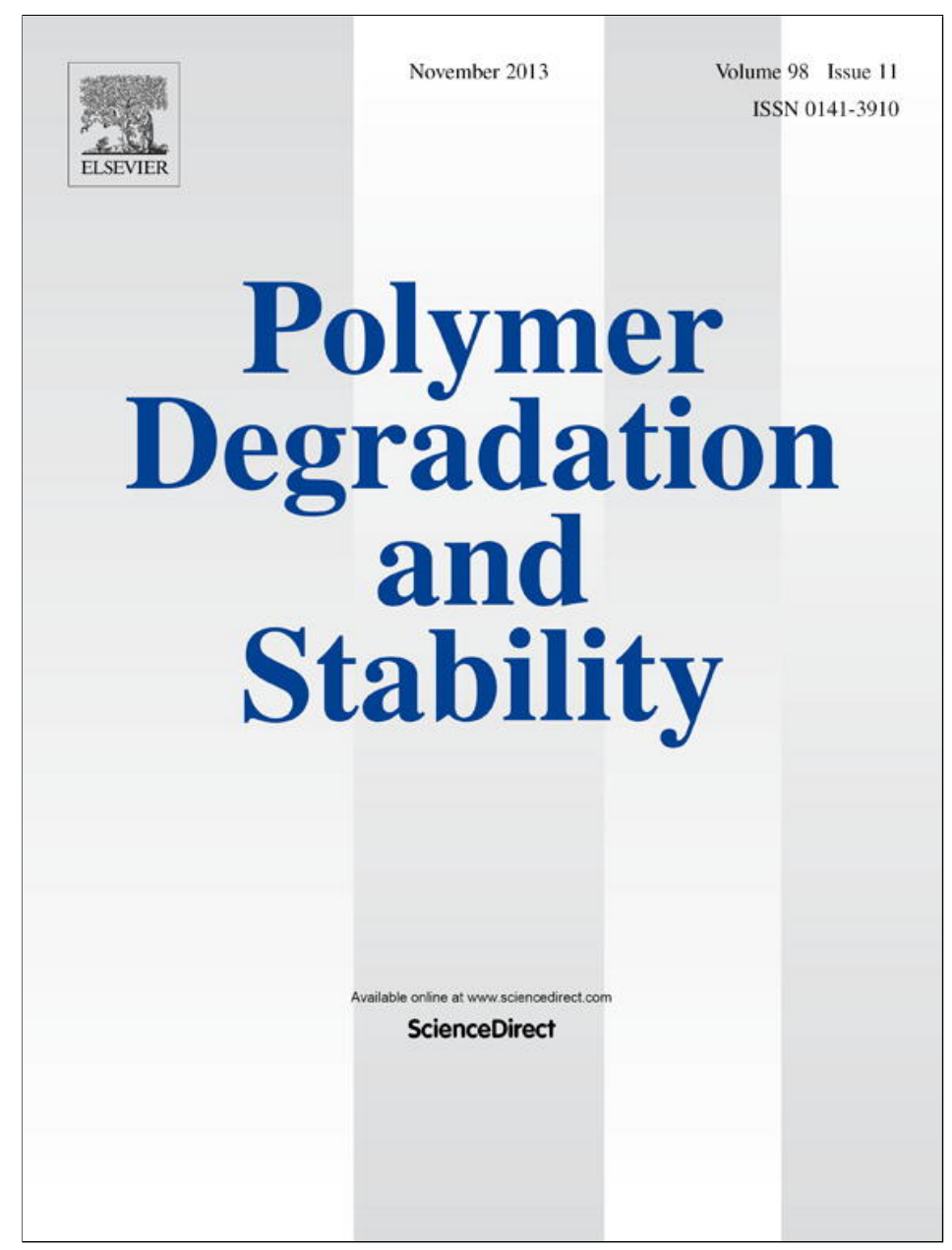

This article appeared in a journal published by Elsevier. The attached copy is furnished to the author for internal non-commercial research and education use, including for instruction at the authors institution and sharing with colleagues.

Other uses, including reproduction and distribution, or selling or licensing copies, or posting to personal, institutional or third party websites are prohibited.

In most cases authors are permitted to post their version of the article (e.g. in Word or Tex form) to their personal website or institutional repository. Authors requiring further information regarding Elsevier's archiving and manuscript policies are encouraged to visit:

http://www.elsevier.com/authorsrights 


\title{
Examining thermal stability and structure property relationships in coatings based on linear aromatic poly(methoxy-thiocyanurate)s
}

\author{
Ian Hamerton*, Brendan J. Howlin, David A. Tilbrook ${ }^{1}$ \\ Department of Chemistry, Faculty of Engineering and Physical Sciences, University of Surrey, Guildford, Surrey GU2 7XH, UK
}

\section{A R T I C L E I N F O}

\section{Article history:}

Received 9 May 2013

Accepted 19 August 2013

Available online 29 August 2013

\section{Keywords:}

Poly(methoxy-thiocyanurate)s

Thermal properties

Isomerisation

Thermal stability

\begin{abstract}
A B S T R A C T
A series of copoly(methoxy-thiocyanurate)s is prepared in good yield and purity, and fully characterised. Many of the resulting polymers, formed at room temperature using phase transfer catalysis, can be cast into films with good resilience and thermal stability (some examples suffer practically no mass loss when held isothermally at $190{ }^{\circ} \mathrm{C}$ and only display appreciable losses when held continuously at $225^{\circ} \mathrm{C}$ ). Char yields of $61-64 \%$ are achieved in nitrogen depending on backbone structure. Some problems were encountered with solubility, particularly with copolymers, which limited molecular weights analysis, but values of $M_{n}=7000-10,000 \mathrm{~g} \mathrm{~mol}^{-1}$ were obtained for the polycyanurate and polythiocyanurate homopolymers. DSC reveals polymerisation exotherms with maxima at $197-207{ }^{\circ} \mathrm{C}\left(\Delta H_{p}=39-48 \mathrm{~kJ} / \mathrm{mol}\right)$, which are believed to be due to isomerisation of the (activation energies span $172-205 \mathrm{~kJ} / \mathrm{mol}$ ), since Xray powder diffraction measurements reveal no evidence of crystalline structure in the resulting product. (C) 2013 Published by Elsevier Ltd.
\end{abstract}

\section{Introduction}

The reactivity of chlorotriazines towards alcohols in the presence of base to produce polymers has been known since its first reports in 1965 [1], although this early work yielded insoluble and intractable crosslinked films. The subsequent use of capped dichlorotriazines to prevent crosslinking meant that linear aromatic polycyanurates could be achieved in a more controllable fashion, although initially high temperatures and basic conditions were required [2]. The pioneering work of Nakamura et al. [3] led to the use of water-immiscible organic solvent in the presence of a cationic phase transfer catalyst (PTC), typically quaternary salts of organic amines, and this was achieved at significantly lower reaction temperatures. In his seminal work, he reported that some 40 newly-prepared alkoxy-cyanurates either decomposed or crosslinked on heating at $200{ }^{\circ} \mathrm{C}$ for $60 \mathrm{~min}$. In an earlier study, we reported [4] the application and refinement of this method to produce a variety of substituted linear polycyanurates and concentrated on the structure-property relationships associated with the polymer backbone. We found that thermal annealing of these materials appeared to lead to both isomerisation and possibly a degree of crystallisation. The present work concentrates on replacing the cyanurate (ether) linkage with sulphur atoms to yield

\footnotetext{
* Corresponding author.

E-mail address: i.hamerton@surrey.ac.uk (I. Hamerton).

1 Current address: Hexcel Composites, Ltd., Duxford, Cambridge CB22 4QD, UK.
}

copoly(methoxy-thiocyanurate)s to enable us to explore the influence of the backbone flexibility on thermal and thermomechanical properties.

\section{Experimental section}

\subsection{Equipment}

Fourier transform infrared (FTIR) spectra were obtained using a Perkin Elmer 1750 FTIR spectrometer interfaced with a Perkin Elmer 7300 computer; a minimum of 24 scans was collected at a resolution of $2 \mathrm{~cm}^{-1}$. Materials that could be cast from solution were analysed directly as films, otherwise diffuse reflectance infrared spectroscopy (DRIFTS) was used. The spectral data are presented in absorbance units to allow easy comparison of the normal transmission spectra with DRIFTS data in Kubelka-Munk units. As the path length was not constant for different samples, no interpretation of the intensities has been made.

${ }^{1} \mathrm{H}$ and ${ }^{13} \mathrm{C}$ nuclear magnetic resonance (NMR) spectra were

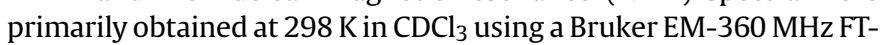
NMR spectrometer equipped with a dual ${ }^{1} \mathrm{H} /{ }^{13} \mathrm{C}$ probe operating at $300 \mathrm{MHz}$ for ${ }^{1} \mathrm{H}$ and $75.5 \mathrm{MHz}$ for ${ }^{13} \mathrm{C}$ respectively. In some instances the distortionless enhancement by polarisation transfer (DEPT) method [5] was to assist in the assignment of the ${ }^{13} \mathrm{C}$ NMR spectra.

Gel permeation chromatography (GPC) was performed using a Waters $150 \mathrm{CV}$ equipped with a dual refractive index (RI)/viscometric detector. Waters $\mu$-Styragel-HT columns $\left(10^{6}, 10^{5}, 10^{4}, 10^{3} \AA\right)$ were employed using $N, N^{\prime}$-dimethylacetamide (with $1 \%$ lithium 
chloride) as the eluent; in all instances the columns were maintained at $60{ }^{\circ} \mathrm{C}$. Calibration was carried out using polysaccharide (dextran) standards with molecular weights ranging from 5800 to $853,000 \mathrm{~g} \mathrm{~mol}^{-1}$.

Differential scanning calorimetry (DSC) was performed using a Shimadzu DSC-50 differential scanning calorimeter. Analyses were performed on samples $(5 \pm 1 \mathrm{mg})$ in nitrogen $\left(25-30 \mathrm{~cm}^{3} \mathrm{~min}^{-1}\right)$ in dynamic mode $\left(10 \mathrm{~K} \mathrm{~min}^{-1}\right.$ from ambient to $490{ }^{\circ} \mathrm{C}$ ). A two-point calibration was carried out using high purity ( $>99.99 \%)$ indium and zinc wire. Glass transition temperature $\left(T_{g}\right)$ values were determined according to ASTM D3418 [6] by heating the sample to above its $T_{g}$, holding it at that temperature to reduce the effect of previous thermal treatments, cooling below $T_{g}$ and then reheating through the $T_{g}$ at $20 \mathrm{~K} \mathrm{~min}^{-1}$.

Thermogravimetric analysis (TGA) was performed using a Shimadzu TGA-50 Thermogravimetric Analyser. Analyses were initially performed on samples $(6 \pm 1 \mathrm{mg})$ in nitrogen $\left(50 \mathrm{~cm}^{3} \mathrm{~min}^{-1}\right)$ and also air $\left(50 \mathrm{~cm}^{3} \mathrm{~min}^{-1}\right)$ in dynamic mode $\left(20 \mathrm{~K} \mathrm{~min}^{-1}\right.$ from ambient to $490{ }^{\circ} \mathrm{C}$ ) and isothermal mode (in which the sample was ramped rapidly at $99 \mathrm{~K} \mathrm{~min}^{-1}$ to the analysis temperature before being maintained for the desired time). A two-point calibration was carried out using high purity ( $>99.99 \%$ ) indium and zinc wire.

X-ray powder diffractograms were obtained for powdered polymer samples (precipitated from solutions of the crude product) using a Philips diffractometer using $\mathrm{Cu}-\mathrm{K} \alpha$ radiation between 10 and $60^{\circ}$. Samples were analysed both prior to and after exposure to a heating programme (room temperature to $300^{\circ} \mathrm{C}$ at a heating rate of $10 \mathrm{~K} / \mathrm{min}$ ) in air.

\subsection{Materials}

Although this programme involved extensive preparative chemistry, in the interests of brevity the details for the preparation and characterisation of the monomers have been deposited as Supplementary information.

\subsubsection{General polymerisation method}

The reaction mixtures comprised one or more bisthiophenols (the dithiols of diphenyl ether, DTPE, and diphenyl sulphide, DTPS, respectively), 2-methoxy-4,6-dichloro-s-triazine (a total of $0.001 \mathrm{~mol}$ of MDCT and the bisthiodiphenol were used in all cases) and Cetrimide (cetrimonium bromide, $6 \mathrm{~mol} . \%$ ) were prepared in dichloromethane $\left(25 \mathrm{~cm}^{3}\right)$ at $30^{\circ} \mathrm{C}$. A solution of sodium hydroxide $(0.2 \mathrm{M})$ in water $\left(100 \mathrm{~cm}^{3}\right)$ was prepared in a 3-necked, $250 \mathrm{~cm}^{3}$ round bottomed flask and degassed (30 min) with a strong flow of nitrogen. To the degassed solution was added the aromatic bisthiophenol under nitrogen (see Table 1 for designations used for the polymers in this paper and specific reagent quantities). To the aqueous phase was added rapidly (with vigorous magnetic stirring at $600 \mathrm{rpm}$ ) the organic phase to yield a homogeneous emulsion. The reaction mixture was raised to the desired polymerisation temperature before being maintained (under a positive pressure nitrogen blanket) isothermally using a thermostatted oil bath. After a measured period of time, stirring was ceased and the emulsion was allowed to settle before the addition of saturated sodium hydrogen carbonate solution or brine $\left(25-50 \mathrm{~cm}^{3}\right)$ to break the emulsion. The organic phase was removed and the aqueous phase was extracted with fresh solvent $\left(2 \times 25 \mathrm{~cm}^{3}\right)$. The organic extracts were then combined and dried over magnesium sulphate before the solvent was removed under reduced pressure. The crude polymer thus produced was purified by dissolution in fresh solvent $\left(50 \mathrm{~cm}^{3}\right)$ and precipitated into a suitable non-solvent $\left(200 \mathrm{~cm}^{3}\right)$. For instance, when dichloromethane or chloroform was used as the organic phase, hexane was used as the non-solvent; when $o$ dichlorobenzene was used, the non-solvent was toluene. The precipitates were then filtered and dried in vacuo $\left(80^{\circ} \mathrm{C}, 24 \mathrm{~h}\right)$ before

Table 1

General preparation and properties of selected linear poly(methoxy-thiocyanurate)s.<smiles>COc1nc(SC)nc(Sc2ccc(Sc3ccc(C)cc3)cc2)n1</smiles>

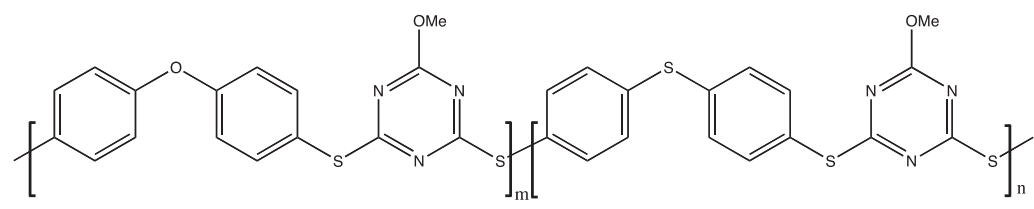

\begin{tabular}{|c|c|c|c|c|c|}
\hline Sample designation & Molar ratio DTPE:MDCT & Molar ratio DTPS:MDCT & Yield (\% theor) & Solubility in $\mathrm{CH}_{2} \mathrm{Cl}_{2}$ & Comments (film thicknesses) \\
\hline DPEMTC & 1 & 0 & 90 & Good $(20 \%)$ & Lossy $(25-50 \mu \mathrm{m})$ \\
\hline DPSMTC & 0 & 1 & 90 & Good (20\%) & Lossy $(15-50 \mu \mathrm{m})$ \\
\hline F1 & 0.5 & 0.5 & 88 & Moderate $^{\mathrm{a}}$ & Lossy $(7-18 \mu \mathrm{m})$ \\
\hline F2 & 0.67 & 0.33 & 89 & Moderate $^{a}$ & Almost opaque $(12-55 \mu \mathrm{m})$ \\
\hline F3 & 0.75 & 0.25 & 94 & Moderate $^{a}$ & Almost opaque $(12-40 \mu \mathrm{m})$ \\
\hline F4 & 0.33 & 0.67 & 90 & Partial $^{\mathrm{b}}$ & Almost opaque $(12-50 \mu \mathrm{m})$ \\
\hline F5 & 0.25 & 0.75 & 100 & Partial $^{\mathrm{b}}$ & Almost opaque $(13-33 \mu \mathrm{m})$ \\
\hline
\end{tabular}

All reactions carried out on $0.01 \mathrm{M}$ scale at $30{ }^{\circ} \mathrm{C}$ using total reaction volume of $125 \mathrm{~cm}^{3}$, total reaction time of $18 \mathrm{~h}$.

Dichloromethane was used as the organic phase with a phase volume ratio (organic volume:aqueous volume) of 0.25 .

$\mathrm{DTPE}=$ dithiol diphenyl ether.

DTPS $=$ dithiol diphenyl sulphide.

MDCT $=$ methoxydichloro-s-triazine

a Some phase separation observed (translucent solution).

b Precipitation from solution on standing - possible fractionation. 
analysis (the elemental analyses were conducted for the polymers and these are given in Supplementary Tables 1 and 2).

\section{Results and discussion}

\subsection{Synthetic procedure}

All of the interfacial polymerisations were performed under phase transfer (PT) conditions using Cetrimide as the phase transfer catalyst (PTC). Initially, the polymerisation was performed using a reported method [7] in which a phase-volume ratio (PVR) of 1 was used and the PTC ( $6 \mathrm{~mol} \%$ ) was added, but later studies suggested that a PVR of 0.25 [8] yielded a high molecular weight product. The deprotonation of the aromatic thiols required a stronger base than was required for the formation of the corresponding bisphenoxides [4] and the time required to achieve dissolution in the aqueous phases was longer; in some cases turbid solutions resulted. All reactions were carried out under nitrogen to prevent termination by oxidation to a quinoid-type structure). Alternatively termination can occur via hydrolysis of a chlorotriazine moiety from the chain or from the formation of a ring [7]. The initial step of the polymerisation involves the formation of a PTC-phenylsulphide adduct, followed directly by chain initiation, and the first stage of chain growth occurs by sequential addition of one equivalent of the 2:1 PTC-bisphenylsulphide adduct. The result is a phenylsulphideterminated chain that is reactive towards the chlorotriazine although chain addition is also possible between growing oligomeric chains bearing groups of complementary reactivity (i.e. a phenylsulphide-terminated oligomer may undergo co-reaction with another bearing a terminal chlorotriazine moiety); the latter yields significantly larger increases in molecular weight than the former step growth mechanism. All polymers exhibited lower then theoretical levels of nitrogen (Supplementary Tables 1 and 2), and these deviations almost certainly stem from incomplete reaction of the monomer and residual solvent.

\subsection{Spectroscopic characterisation of the polymers}

All of the linear polymers in the series exhibited similar vibrational spectra and the majority of the bands are attributable to characteristic structural motifs (Table 3, Supplementary material). Many of the bands unique to different aromatic bisphenyl linking groups are hidden below the stronger aromatic ring modes, but all of the polymers exhibit a strong band between 1220 and $1190 \mathrm{~cm}^{-1}$ and the symmetrical mode in which the $\mathrm{C}-\mathrm{O}$ stretches are coupled to the symmetrical triazine ring breathing motion appears as a band at $1390 \mathrm{~cm}^{-1}$. Padgett and Hamner [9] postulated that the band close to $1220 \mathrm{~cm}^{-1}$, which is common to all the tri-substituted cyanurates, was due to a second mode involving a $\mathrm{C}-\mathrm{O}$ stretch correlated to motion of the substituents around the cyanurate system. Samples of DPEMTC, DPSMTC and the copolymers were analysed by ${ }^{1} \mathrm{H}$ and ${ }^{13} \mathrm{C}$ NMR spectroscopy (Tables 4 and 5 , supplementary material) with DEPT analysis used to assist the identification of the different carbon atoms. ${ }^{1} \mathrm{H}$ NMR data are in good agreement with those reported in the literature for other linear polycyanurates [10-12] with the methoxy protons falling between 3.94 and $3.98 \mathrm{ppm}$.

Shifts attributable to long chain methylene protons (1.24 ppm) and the methyl protons on the trimethyl $C_{18}$ ammonium ion (3.3 ppm) indicated the presence of residual Cetrimide apparent in all samples. Comparison of the ${ }^{1} \mathrm{H}$ NMR spectrum of DPEMTC with that of the cyanurate analogue DPEMC [4] shows that the use of thiocyanurates increases the difference in chemical shift between the aromatic protons ortho- and meta- to the triazine ring as well as reducing the chain relaxation time. This is in good agreement with published substituent effects on the proton chemical shifts of

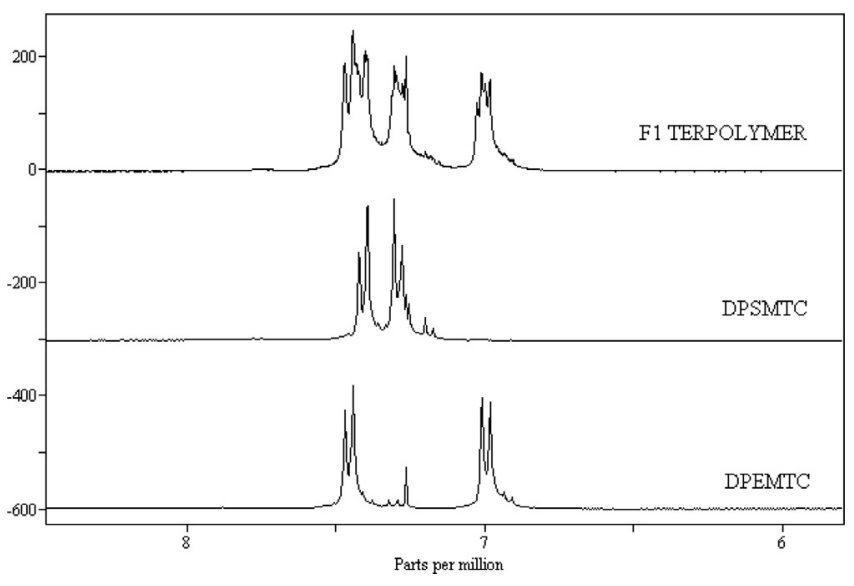

Fig. 1. ${ }^{1} \mathrm{H}$ NMR spectra of selected linear poly(methoxy-thiocyanurate)s.

substituted benzenes and with literature values for linear [12] and crosslinked polycyanurates $[13,14]$. The thioether moiety shifts the signal of the ortho- protons approximately $0.4 \mathrm{ppm}$ downfield. The ${ }^{13} \mathrm{C}$ chemical shifts for the triazine ring are in excellent agreement with published values and the resonance at $183 \mathrm{ppm}$ is in keeping with an aromatic carbon with an ipso-methoxy group. The replacement of the ether linkage with a thioether to yield DPSTMC results in equilibration of the charge density along the backbone of the polymer, which is indicated by the increased proximity of the signals for the two secondary carbon atoms in the polymer backbone. The replacement of the ether linkage also has a marked effect on the positions of the signals attributed to the phenylene quaternary carbons. All these effects are consistent with increasing the similarity in the environments of the backbone carbons. The NMR spectra of the terpolymers contain shifts corresponding to both copolymers (DPEMTC and DPSMTC), although some broadening of $\mathrm{C}-\mathrm{H}$ proton signals is observed in the ${ }^{1} \mathrm{H}$ NMR spectrum of (F1) (Fig. 1). This is probably due to the introduction of slight variations in the backbone conformation as a result of terpolymer formation. The relative intensities of the two sets of peaks support random incorporation of the two different bisthiodiphenols. The ${ }^{13} \mathrm{C}$ NMR spectrum of $\mathrm{F} 1$ is a straightforward combination of the spectra of DPEMTC and DPSMTC (Fig. 2).

\subsection{The dependence of molecular weight distribution on molecular structure}

Although all the copolymers formed from the commercial bisthiols were soluble in chloroform and dichloromethane, they were

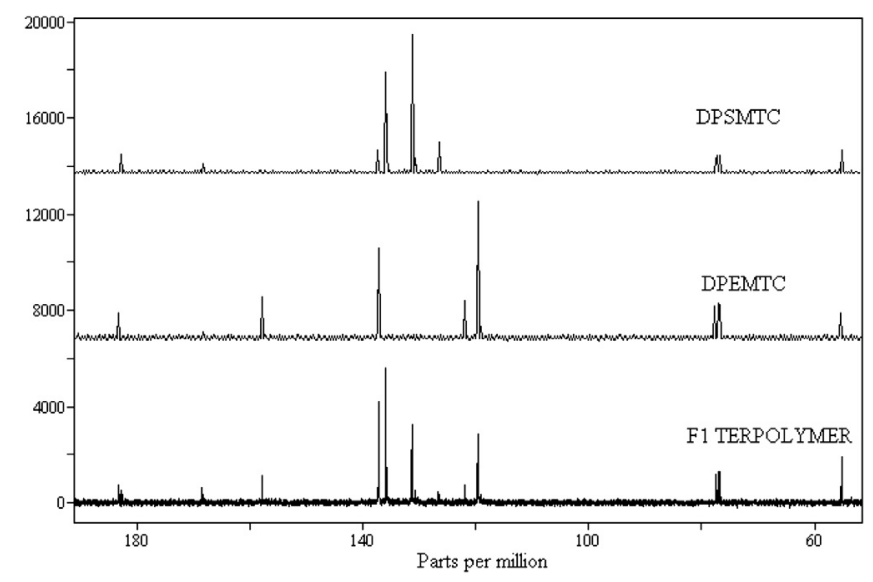

Fig. 2. ${ }^{13} \mathrm{C}$ NMR spectra of spectra of selected linear poly(methoxy-thiocyanurate)s. 
Table 2

Molecular weight averages for linear copoly(methoxy-thiocyanurate)s.

\begin{tabular}{|c|c|c|c|c|c|c|c|c|}
\hline \multirow[t]{2}{*}{ Sample } & \multicolumn{5}{|c|}{ Molecular weight averages (Daltons) } & \multirow[t]{2}{*}{$M_{w} / M_{n}$} & \multirow[t]{2}{*}{$x_{n}$} & \multirow[t]{2}{*}{$p$} \\
\hline & $M_{n}$ & $M_{p}$ & $M_{w}$ & $M_{z}$ & $M_{z+1}$ & & & \\
\hline DPEMTC & 10,000 & 32,000 & 45,000 & 104,000 & 171,000 & 4.32 & 59 & 0.983 \\
\hline DPSMTC & 7000 & 19,000 & 23,000 & 48,000 & 73,000 & 3.29 & 39 & 0.974 \\
\hline
\end{tabular}

insoluble in DMAc and could not be analysed by GPC using our instrumentation. However, the samples of DPSMTC and DPEMTC were analysed and the data are given below (Table 2). A stoichiometrically weighted average of the two repeat units was used in conjunction with $M_{n}$ in the Carothers' equation [15] for an A-A/B$B$ polymer to calculate the number average degree of polymerisation $\left(x_{n}\right)$ and the extent of monomer conversion $(p)$ for each material. The polymers have very broad molecular weight distributions, which is not uncommon in the early stages of condensation polymerisations. The breadth of the distributions even in the samples with high molecular weight suggests that at high degrees of conversion the reaction is being terminated by either diffusion control or hydrolysis of the active terminal groups. The polymerisation is an example of a step growth addition mechanism, but this is only truly the case once all the bisthiol monomer has been carried across into the organic phase by the PTC.

All of the polymers were soluble in dichloromethane or chloroform to give viscous solutions, which could be readily cast as films that could be released from glass plates for analysis. On standing all of the solutions became turbid and for samples F1, F2 and F3 this resulted in translucent solutions that could not be cleared by filtration. Precipitates formed from solutions of F4 and F5 that would not re-dissolve with either addition of more solvent or warming. Addition of further dichloromethane reduced the viscosity of the solutions sufficiently to allow them to be filtered before being concentrated on the rotary evaporator. Films cast from these freshly filtered solutions showed signs of phase separation on drying, which resulted in fine white dendrites becoming visible in the bulk of the film. Milder phase separation occurred in all terpolymers resulting in the formation of lossy films. FTIR spectra were obtained of the precipitates obtained from the solutions of the terpolymers and were consistent with the polymer in the mother solution, suggesting that partial solvent-induced crystallisation. Similar behaviour has been reported by Kondo et al. [16] who studied the copolymerisation of DTPS with a number of dichlorotriazines (other than MDCT).

\subsection{Influence of polymer structure on thermal and thermo- oxidative stability}

All of the polymers were analysed for their thermal stability by dynamic TGA. The analyses were carried out between ambient and $490{ }^{\circ} \mathrm{C}$ at an atmospheric flow rate of $50 \mathrm{~cm}^{3} \mathrm{~min}^{-1}$ and a

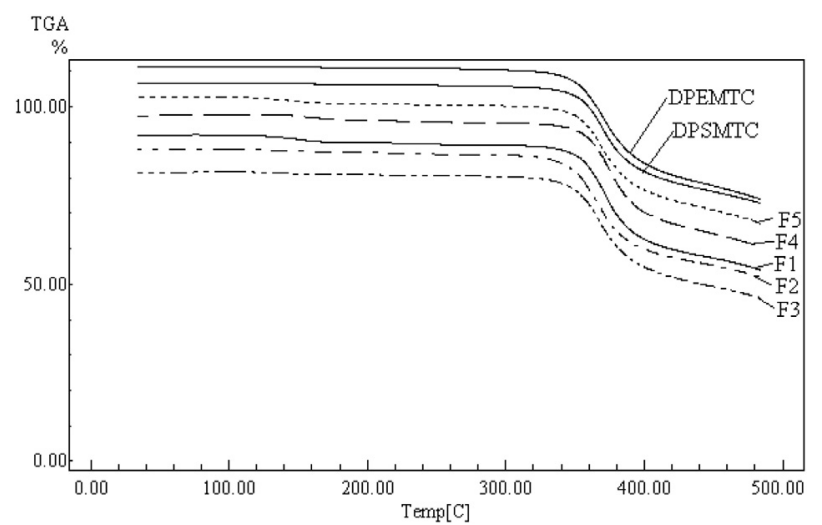

Fig. 3. TGA curves for selected linear poly(methoxy-thiocyanurate)s under nitrogen (heating rate $20 \mathrm{~K} \mathrm{~min}^{-1}$, flow rate $50 \mathrm{~cm}^{3} \mathrm{~min}^{-1}$ ).

heating rate of $20 \mathrm{~K} \mathrm{~min}^{-1}$. The TGA data are summarised in Table 3 and the TGA curves for selected polymers are shown in Fig. 3. All the samples displayed similar stability in nitrogen and the onsets of decomposition were of comparable magnitude to those observed for poly(methoxy-cyanurate)s [4] and poly(ethoxy-cyanurate)s $[8,17]$, with the primary differences being that the poly(methoxy-thiocyanurate)s exhibit a slightly higher char yield at $490{ }^{\circ} \mathrm{C}$ (average char yield 62\%). A dynamic TGA study of DPEMTC from ambient to $1000{ }^{\circ} \mathrm{C}$ in nitrogen showed that decomposition proceeds via a three-stage mechanism. The initial phase of the degradation $\left(300-400{ }^{\circ} \mathrm{C}\right.$, maximum $375{ }^{\circ} \mathrm{C}$ ) precedes a significant mass loss, in a higher temperature regime (maximum $550{ }^{\circ} \mathrm{C}$ ). This major mass loss is observed in all polycyanurates and has been found to be due to decyclisation of the triazine ring, liberating volatile decomposition products. Walters et al. [18] attributed this step to decyclisation of the cyanurate to the corresponding isocyanurate followed by reaction with moisture to form carbamates. The latter underwent further hydrolysis to yield carbamic acid, that decomposes spontaneously to form carbon dioxide and ammonia. The formation of char occurs above $600{ }^{\circ} \mathrm{C}$ (maximum $700{ }^{\circ} \mathrm{C}$ ) and the yield was less than $3 \%$ at $1000{ }^{\circ} \mathrm{C}$. DPEMTC was analysed isothermally in both air and nitrogen under nitrogen (Table 4) and the homopolymer exhibited similar thermal stability to its cyanurate analogue $[4]$ and at temperatures below $225^{\circ} \mathrm{C}$ mass loss is negligible. The early mass loss observed in all of the isothermal experiments is believed to be due to the release of trapped solvent rather than polymer degradation. At $225{ }^{\circ} \mathrm{C}$ in nitrogen any degradation resulting in mass loss appears to reach a plateau at a mass loss of $2 \%$; under the same conditions in air, the mass of the sample decreases continuously so that after $400 \mathrm{~min}$ the drop is almost linear with time to give a total mass loss of $9 \%$ after 1000 min (Fig. 4).

Table 3

Thermal stability of linear poly(methoxy-thiocyanurate)s in nitrogen (heating rate $20 \mathrm{~K} \mathrm{~min}^{-1}$, u flow rate $50 \mathrm{~cm}^{3} \mathrm{~min}^{-1}$ ).

\begin{tabular}{llllllll}
\hline Polymer & $T_{1 \%}\left({ }^{\circ} \mathrm{C}\right)^{\mathrm{a}}$ & $T_{2 \%}\left({ }^{\circ} \mathrm{C}\right)$ & $T_{3 \%}\left({ }^{\circ} \mathrm{C}\right)$ & $T_{5 \%}\left({ }^{\circ} \mathrm{C}\right)$ & $T_{10 \%}\left({ }^{\circ} \mathrm{C}\right)$ & $T_{20 \%}\left({ }^{\circ} \mathrm{C}\right)$ & $T_{\text {max }}\left({ }^{\circ} \mathrm{C}\right)^{\mathrm{b}}$ \\
\hline DPEMTC & 288 & 333 & 343 & 353 & 364 & 380 & 371 \\
DPSMTC & 303 & 337 & 347 & 356 & 366 & 383 & 371 \\
F1 & 149 & 193 & 320 & 348 & 363 & 377 \\
F2 & 174 & 295 & 341 & 356 & 368 & 383 & 372 \\
F3 & 142 & 203 & 324 & 349 & 363 & 380 & 375 \\
F4 & 224 & 321 & 334 & 347 & 359 & 374 \\
F5 & 256 & 328 & 340 & 350 & 362 & 379 \\
\hline
\end{tabular}

a $T_{x \%}=$ temperature at which $x \%$ weight loss is observed.

b Temperature of maximum weight loss determined from first derivative of weight loss curve. 
Table 4

Isothermal TGA data for DPEMTC in nitrogen and air.

\begin{tabular}{|c|c|c|c|c|c|c|c|c|}
\hline Temperature $\left({ }^{\circ} \mathrm{C}\right)$ & Atmosphere & $T_{0.25 \%}(\mathrm{~min})$ & $T_{0.50 \%}(\mathrm{~min})$ & $T_{1 \%}(\min )$ & $T_{2 \%}(\min )$ & $T_{5 \%}(\min )$ & $T_{10 \%}(\min )$ & $\%$ wt. loss at $1000 \mathrm{~min}$ \\
\hline \multirow[t]{2}{*}{190} & Nitrogen & - & - & - & - & - & - & 100 \\
\hline & Air & - & - & - & - & - & - & 100 \\
\hline \multirow[t]{2}{*}{225} & Nitrogen & $<2$ & $<2$ & - & - & - & - & 99 \\
\hline & Air & $<2$ & $<2$ & 203 & 413 & 691 & - & 91 \\
\hline \multirow[t]{2}{*}{300} & Nitrogen & 7 & 16 & 33 & 49 & 87 & 139 & 78 \\
\hline & Air & $<1$ & $<1$ & 14 & 17 & 24 & 34 & 81 \\
\hline
\end{tabular}

\subsection{Comparison of kinetics of thermal conversion of co- and} terpoly(methoxy-thiocyanurate)s

The following heating programme (heat cycle 1 from 25 to $300{ }^{\circ} \mathrm{C} @ 10 \mathrm{~K} / \mathrm{min}$; cool 300-70 ${ }^{\circ} \mathrm{C} @-10 \mathrm{~K} / \mathrm{min}$ and hold for $10 \mathrm{~min}$; heat cycle 2 from 70 to $300{ }^{\circ} \mathrm{C} @ 20 \mathrm{~K} / \mathrm{min}$ ) was used for all samples. The foregoing analysis using TGA had revealed no significant decomposition at $300{ }^{\circ} \mathrm{C}$ under nitrogen. On the first heating cycle two thermal events were commonly evident: a weak endotherm (observed in F1, F2 and F4, Fig. 5(a)) was possibly a glass transition (modulated DSC was not available to us at this time) and the other a prominent exotherm; the temperatures corresponding to these are denoted $T_{g 1}$ and $T_{p}$ respectively (Table 5). The enthalpy of the polymerisation exotherm, $\Delta H_{p}$, was calculated using a standard method [19] and is expressed in terms of $\mathrm{J} \mathrm{g}^{-1}$ and $\mathrm{kJ} \mathrm{mol}^{-1}$ (with respect to the structural repeat unit of the polymer chain). On the second heating cycle all samples exhibited an increase in heat capacity, consistent with the observation of a glass transition temperature (denoted $T_{g 2}$ ), between the onset and endset temperatures of the exotherm in the first heating cycle. The exotherms are generally very similar for all the samples analysed in this work and also to other data reported by other workers for poly(methoxy-cyanurate)s subjected to similar heating cycles [6,9,10,20-22]. Although Braun and Ziser [8,17], who worked extensively with 2,4-dichloro-6-ethoxy-triazine, did not report exothermic behaviour in their samples, we have observed similar behaviour in poly(methoxy-cyanurate)s [4].

The exothermic peaks observed in the DSC thermograms were analysed using the method of Sun et al. [23] on the assumption that a single first order process was responsible for the exotherm. The method is based on the fact that the kinetics of any process, which results in the conversion of a material from one form to another, can be described by Eq (1).

$\frac{1}{A}\left(\frac{\partial H}{\partial t}\right)_{T}=k_{0}\left[1-\frac{A_{t}}{A}\right]^{n} e^{-E_{a} / R T}$

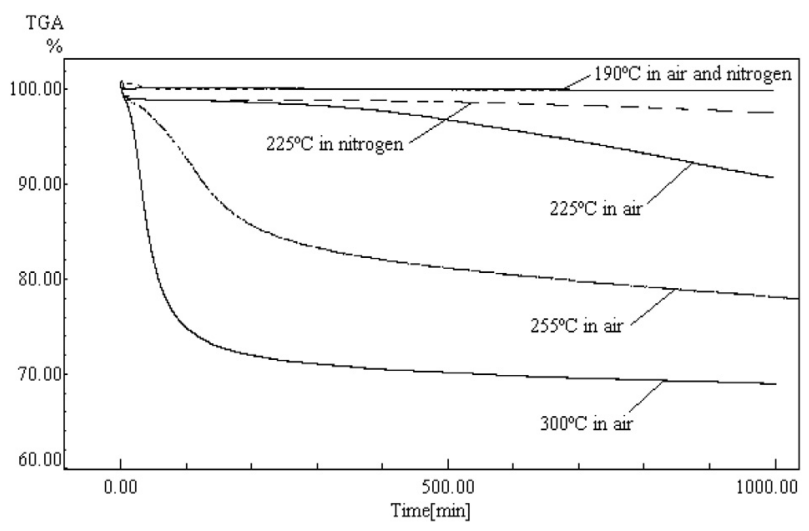

Fig. 4. Isothermal TGA curves for DPETMC in nitrogen and air. where $A=$ the integral under the DSC exotherm, $A_{t}=$ the integral under the DSC curve from $T_{\mathrm{ip}}$ to $T, E_{a}$ is the activation energy, $R=8.31451 \mathrm{~J} \mathrm{~K}^{-1} \mathrm{~mol}^{-1}, n=$ order of reaction.

As $A, A_{t}$ and $\partial H / \partial t$ can be obtained from the DSC curve it is possible to calculate a value for $k(T)$ for each temperature. If the reaction is first order (i.e. $n=1$ ), it follows that a plot of $\ln k(T)$ against $1 / T$ should give a straight line, whose gradient will yield $E_{a}$ and $k_{0}$ for the overall process. The temperature range over which the data fitted the first order kinetic model for each polymer and the quality of fit $\left(R^{2}\right)$ is summarised in Table 6 (deviation from linearity is observed at the extremes of the temperatures range), but the model applies very well over a wide temperature range corresponding to around $93-97 \%$ of the total observed exotherm.

The DSC rescan curves of the poly(methoxy-thiocyanurate)s (Fig. 5(b)) display some differences from previously reported cyanurate analogues [4] as the latter tend to exhibit single glass transitions of variable intensity between 190 and $220^{\circ} \mathrm{C}$, while the transitions for the thiocyanurate polymers are found at lower temperatures $\left(144-175^{\circ} \mathrm{C}\right)$. This is consistent with our earlier

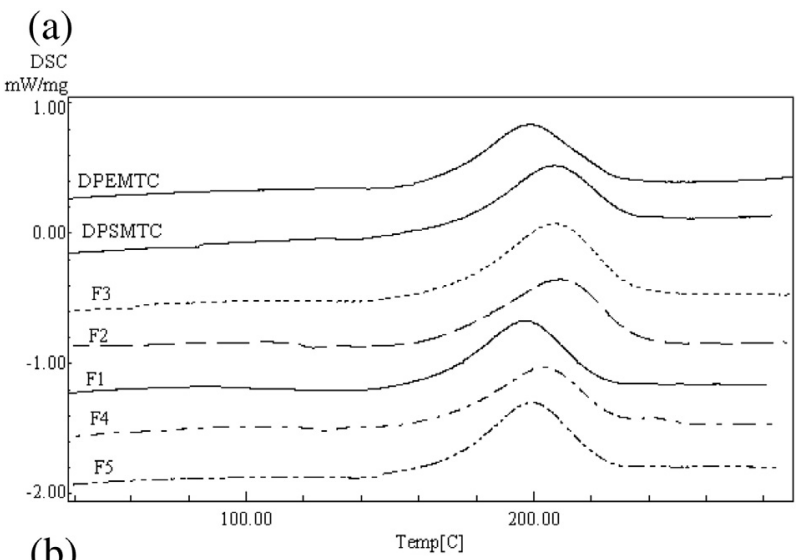

(b)

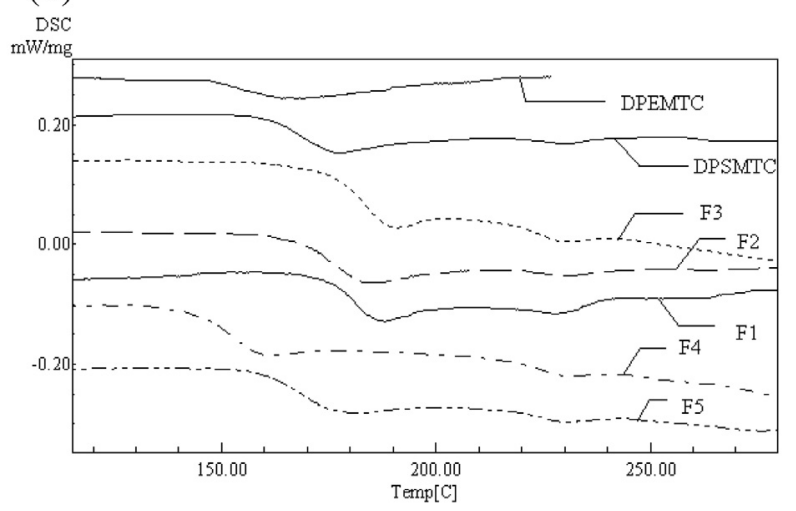

Fig. 5. (a) DSC curves for selected linear poly(methoxy-thiocyanurate)s (heating rate $10 \mathrm{~K} \mathrm{~min}^{-1}$ ) and (b) rescan (heating rate $20 \mathrm{~K} \mathrm{~min}^{-1}$ ) flow rate under nitrogen $\left(30 \mathrm{~cm}^{3} \mathrm{~min}^{-1}\right)$. 
Table 5

Thermal events for linear poly(methoxy-thiocyanurate)s as determined by DSC.

\begin{tabular}{|c|c|c|c|c|c|c|c|c|c|}
\hline \multirow[t]{2}{*}{ Polymer } & \multirow[t]{2}{*}{$T_{g 1}\left({ }^{\circ} \mathrm{C}\right)$} & \multirow[t]{2}{*}{$T_{\text {ip }}^{\prime}\left({ }^{\circ} \mathrm{C}\right)$} & \multirow[t]{2}{*}{$T_{\text {ip }}\left({ }^{\circ} \mathrm{C}\right)$} & \multirow[t]{2}{*}{$T_{p}\left({ }^{\circ} \mathrm{C}\right)$} & \multirow[t]{2}{*}{$T_{\text {ep }}\left({ }^{\circ} \mathrm{C}\right)$} & \multirow[t]{2}{*}{$T_{\text {ep }}\left({ }^{\circ} \mathrm{C}\right)$} & \multicolumn{2}{|l|}{$\Delta H_{p}$} & \multirow[t]{2}{*}{$T_{\mathrm{g} 2}\left({ }^{\circ} \mathrm{C}\right)$} \\
\hline & & & & & & & $\left(\mathrm{J} \mathrm{g}^{-1}\right)$ & $\left(\mathrm{kJ} \mathrm{mol}{ }^{-1}\right)$ & \\
\hline DPEMTC & 130 & 146 & 157 & 200 & 230 & 256 & 120 & 41.0 & - \\
\hline DPSMTC & 129 & 146 & 174 & 207 & 233 & 254 & 110 & 39.3 & 174 \\
\hline F1 & 91 & 136 & 164 & 197 & 226 & 248 & 120 & 41.9 & 160 \\
\hline F2 & 116 & 140 & 168 & 210 & 236 & 257 & 120 & 41.6 & 168 \\
\hline F3 & 107 & 140 & 174 & 207 & 235 & 254 & 140 & 48.3 & 175 \\
\hline F4 & 121 & 134 & 164 & 204 & 230 & 263 & 110 & 38.7 & 144 \\
\hline F5 & - & 145 & 169 & 200 & 225 & 237 & 120 & 42.4 & 150 \\
\hline
\end{tabular}

$T_{g 1}=$ Possible glass transition of polymer determined using a heating rate of $10 \mathrm{~K} \mathrm{~min}^{-1}$.

$T_{\mathrm{ip}}=$ Observed onset of polymerisation.

$T_{\text {ip }}=$ Observed onset of polymerisation.

$T_{i \mathrm{p}}^{\prime}=$ Extrapolated onset of polymerisation (from triangulation of apex of polymerisation exotherm).

$T_{p}=$ Temperature of exothermic peak maximum.

$T_{p}=$ Temperature of exothermic peak maximum.

$T_{\mathrm{ep}}^{\prime}=$ Extrapolated end of polymerisation (from triangulation of apex of polymerisation exotherm).

$T_{\mathrm{ep}}=$ Observed end of polymerisation.

$\Delta H_{p}=$ Enthalpy of exothermic peak.

$T_{g 2}=$ Glass transition temperature of polymer determined using a heating rate of $20 \mathrm{~K} \mathrm{~min}^{-1}$.

molecular simulation data [4] that suggest that the potential barriers to rotation for the aromatic sulphide linkages are somewhat lower (e.g. $14.90 \mathrm{kcal} \mathrm{mol}^{-1}$ cf $20.59 \mathrm{kcal} \mathrm{mol}^{-1}$ ) than the corresponding aromatic ether linkages. In the DSC traces of the cyanurate polymers, no transitions, other than the glass transition drop in $C_{p}$ were discernible, but the poly(methoxy-thiocyanurate)s behave differently: a very weak endotherm is observed consistently in all the copolymers (and DPSMTC) close to $230{ }^{\circ} \mathrm{C}$, but is altogether absent in DPEMTC (even following further annealing at $300^{\circ} \mathrm{C}$ ). The nature of the weak transition is not clear, but the aforementioned TGA data showed negligible weight losses below $250{ }^{\circ} \mathrm{C}$. It is plausible that it is due to a partially annealed amorphous phase containing very small, poorly-formed crystallites, but the XRPD data do not support this. A sample of $\mathrm{F} 1$ was also heated at $10 \mathrm{~K} / \mathrm{min}$ from ambient to $300{ }^{\circ} \mathrm{C}$ then cooled at $10 \mathrm{~K} / \mathrm{min}$ to $70{ }^{\circ} \mathrm{C}$, held at $70{ }^{\circ} \mathrm{C}$ for $15 \mathrm{~min}$ and re-heated at $20 \mathrm{~K} / \mathrm{min}$ to $300{ }^{\circ} \mathrm{C}$, before immediate removal from the furnace. Inspection of the CHN ratios (Supplementary, Table 1) for the heated sample (F1ANN) show that very little change in composition resulted. Elemental analysis, calculated for $\mathrm{C}_{32} \mathrm{H}_{22} \mathrm{~N}_{6} \mathrm{O}_{3} \mathrm{~S}_{5}$ : $54.99 \% \mathrm{C}, 3.17 \% \mathrm{H}, 12.03 \% \mathrm{~N}$; Found: $55.78 \% \mathrm{C}, 3.09 \% \mathrm{H}, 11.02 \% \mathrm{~N}$. Theoretical ratios $\mathrm{C} / \mathrm{N}(4.57), \mathrm{C} / \mathrm{H}$ (17.33), N/H (3.79); found after heating: $\mathrm{C} / \mathrm{N}(5.06), \mathrm{C} / \mathrm{H}(18.08), \mathrm{N} / \mathrm{H}$ (3.57). This supports the hypothesis for isomerisation above $200{ }^{\circ} \mathrm{C}$ which could not be accounted for by loss of solvent.

Additional spectroscopic analysis was performed on DPEMTC in an attempt to identify the nature of the thermal event. FTIR spectra were acquired before and after heating to $300{ }^{\circ} \mathrm{C}$ in air and a strong band was observed to increase in intensity at $1703 \mathrm{~cm}^{-1}$, consistent with the production of a cyclic amide. Whilst no data are available for thiocyanurates, it has been

Table 6

Kinetic parameters for exotherm observed in DSC analysis of linear poly(methoxythiocyanurate)s.

\begin{tabular}{llllll}
\hline Polymer & $\begin{array}{l}\text { Upper } \\
\text { temperature } \\
\left({ }^{\circ} \mathrm{C}\right)\end{array}$ & $\begin{array}{l}\text { Lower } \\
\text { temperature } \\
\left({ }^{\circ} \mathrm{C}\right)\end{array}$ & $\begin{array}{l}\text { Linear range } \\
\text { (corresponding } \\
\text { to } \Delta H, \%)\end{array}$ & $R^{2}$ & $\begin{array}{l}E_{a} \\
\left(\mathrm{~kJ} \mathrm{~mol}^{-1}\right)\end{array}$ \\
\hline DPEMTC & 229 & 157 & 97.4 & 0.994 & 204 \\
DPSMTC & 232 & 161 & 95.7 & 0.990 & 186 \\
F1 & 225 & 161 & 94.5 & 0.996 & 205 \\
F2 & 236 & 154 & 97.9 & 0.990 & 189 \\
F3 & 226 & 148 & 92.9 & 0.992 & 172 \\
F4 & 228 & 142 & 94.2 & 0.998 & 179 \\
F5 & 218 & 156 & 93.0 & 0.991 & 186 \\
\hline
\end{tabular}

known for many years that purely aliphatic cyanurates can be thermally unstable and isomerise readily to yield the corresponding isocyanurate. Trimethoxy-s-triazine isomerises in the vapour phase when heated above $265{ }^{\circ} \mathrm{C}$, with an enthalpy of $202.6 \mathrm{~kJ} / \mathrm{mol}$ [22]; to give an reasonable estimate for the enthalpy of isomerisation of a single methoxy-cyanurate unit, this figure was divided by a third $(65.5 \mathrm{~kJ} / \mathrm{mol})$. The greatly reduced enthalpy observed in the DSC analysis of diphenoxymethoxy-striazine $(13.6 \mathrm{~kJ} / \mathrm{mol})$ suggests that partial isomerisation may be taking place. This is consistent with the findings of Tosato and Soccorsi who have shown, using NMR, that methyl transfer takes place between the methoxy oxygen and one of the two equivalent nitrogen atoms on the triazine ring at temperatures close to $200{ }^{\circ} \mathrm{C}$ in methoxy-cyanurates $[24,25]$. This is further supported by the loss of the triazine vibrational mode at $736 \mathrm{~cm}^{-1}$ following the introduction of an exo-carbonyl group on the isocyanurate ring.

\section{Conclusions}

Aromatic bisthiophenols have been polymerised with dichlorotriazines to form high molecular weight materials in an analogous fashion to aromatic bisphenols. Differences in the solubility and thermal behaviour are observed between poly(methoxythiocyanurate)s and poly(methoxy-cyanurate)s; the former appear to undergo partial crystallisation from dichloromethane which may lead to fractionation of the polymer - behaviour that was not observed with poly(methoxy-cyanurate)s. Partial crystallisation or phase separation might explain the brittle behaviour of some of the thiocyanurate films compared with their cyanurate analogues. Increasing the proportion of sulphur-triazine bonds in the backbone of the polymers leads to a reduction in their glass transition temperatures and an increase in brittleness. When heated to $300^{\circ} \mathrm{C}$ in air, DPEMTC shows no sign of crystallinity from XRPD data, which supports the view that crystallisation is not responsible for the exotherms in the vicinity of $200^{\circ} \mathrm{C}$. However, spectral evidence showing the formation of an amide-like carbonyl functionality is consistent with the thermal isomerisation of the methoxycyanurate moiety.

\section{Acknowledgements}

We thank the Ministry of Defence (formerly DRA, Malvern) for providing sponsorship in the form of a studentship (DAT). 


\section{Appendix A. Supplementary data}

Supplementary data related to this article can be found at http:// dx.doi.org/10.1016/j.polymdegradstab.2013.08.023.

\section{References}

[1] Picklesmeyer LG, Saunders TF. J Polym Sci A, Polym Chem 1996;3:2679.

[2] Audebert R, Néel J. Comptes Rendus Acad Sci Paris 1964;T258:4749.

[3] Nakamura Y, Mori K, Tamura K, Saito Y. J Polym Sci A, Polym Chem 1969;7:3089.

[4] Hamerton I, Howlin BJ, Tilbrook DA. React Func Polym 2013 [in press].

[5] Barron PF, Hill DJT, O'Donnel JH, O'Sullivan PW. Macromolecules 1994;17:1967.

[6] Shimadzu Corporation. DSC-50 service manual; 1993.

[7] Shah PP. J Macromol Sci Chem Ed 1984:84:715.

[8] Braun D, Ziser T. Angew Makromol Chem 1994:219:27.

[9] Padgett WM, Hamner WF. J Am Chem Soc 1958;80:803.

[10] Vargani V, Kansard SS, Patel NK. J Macromol Sci 1991;A28:193.
[11] Kalola SH, Parsania PH. J Polym Mater 1994;11:101.

[12] Kamani MM, Parsania PH. J Polym Mater 1995;12:49.

[13] Fang T. Macromolecules 1991;24:444.

[14] Fyfe CA, Niu J, Rettig SJ, Burlinson NE. Macromolecules 1992;25:6289.

[15] Cowie JMG. Polymers: chemistry and physics of modern materials. New York: John Wiley-Science; 1991.

[16] Kondo S, Mori H, Kadomatsu M, Sato K, Ando T, Kakuno T, et al. J Macromol Sci - Pure Appl Chem 1996;A33:811-9.

[17] Braun D, Most D, Ziser T. Angew Makromol Chem 1994;221:187.

[18] Ramirez ML, Walters R, Lyon RE, Savitski EP. Polym Degrad Stab 2002;78: $73-82$.

[19] Japanese Standard JIS K 7122. Thermal analysis of polymeric materials. Shimadzu Corporation; 1992.

[20] Parsania PH, Shah PP, Patel KC, Patel RD. Angew Makromol Chem 1984;138:139.

[21] Parsania PH, Patel KC, Patel RD. J Polym Sci B, Polym Phys 1984;23:199.

[22] Kalola SH, Gelam PH, Parsania PH. J Polym Mater 1994;11:57.

[23] Sun T, Pereriera J, Porter RS. J Polym Sci B, Polym Phys 1984;22:1163.

[24] Tosato ML, Soccorsi L. J Chem Soc Perkin II 1982:1321.

[25] Tosato ML, Soccorsi L. J Chem Soc Perkin II 1984:1593. 